\title{
An outstanding Saharan Dust event at Mt. Cimone (2165 m a.s.l., Italy) in March 2004
}

\author{
Laura Tositti ${ }^{\mathrm{a},}{ }^{,}$, Erika Brattich ${ }^{\mathrm{a}, \mathrm{b}, *}$ and Angelo Riccio ${ }^{\mathrm{c}}$
}

${ }^{a}$ Environ. Chemistry and Radioactivity Lab., Dept. of Chemistry "G. Ciamician", Alma Mater

Studiorum University of Bologna, Via Selmi 2, 40126 Bologna (BO), Italy

${ }^{b}$ Dept. of Earth and Geological-Environmental Sciences, Alma Mater Studiorum University of

Bologna, Piazza di Porta San Donato, 1, 40126 Bologna (BO), Italy

${ }^{c}$ Dept. of Applied Science, University of Napoli "Parthenope", Centro Direzionale - Isola C4, 80143 Napoli

*erika.brattich@unibo.it

Dust outbreaks are very common throughout the year, with a peak frequency in spring (March, April, May) towards the Atlantic Ocean, or in late spring/summer (May, June, July) towards the Mediterranean Sea (even if winter and especially autumn events, though less frequent, are usually very intense). Every year strong winds blowing over the Sahara desert lift hundreds of millions of tons of dust high into the sky over North Africa.

In 2004, from 13 to 15 March, a severe PM episode was observed at Mt. Cimone. Figure 1, showing the trend of PM10, ${ }^{210} \mathrm{~Pb}$, number of fine and coarse particles, for the year 2005 , highlights a clear increase of all these parameters during the Saharan Dust episode. In particular, PM concentration exceeded 80 $\mu \mathrm{g} / \mathrm{SCM}$, a value seven times greater than the mean level during the preceding and subsequent days, and the maximum PM10 concentration recorded at Mt Cimone in more than 12 years observations. This episode has been ascribed to a long lasting Saharan dust outbreak, starting at the beginning of March, and first impacting the Atlantic Ocean and then the Mediterranean area.

This event originated from the Bodele depression in northern Chad, a remarkable as well as well recognized source of mineral dust, and the analysis of aerosol optical depth revealed that dustiness conditions occurred along the entire ITCZ. On 5th March 2004 images from the visible channel of the SeaWIFS satellite show a huge, dense, meridionally oriented dust plume off the northwestern African coast from west of Madeira to Cape Verde, sustained by hazy and prolonged Harmattan conditions. This plume spreads laterally, moves westward and formed an arc more than $5000 \mathrm{~km}$ long from Guinea to the northern tip of Morocco. The plume crossed the Atlantic Ocean and impacted onto the Caribbean region. 

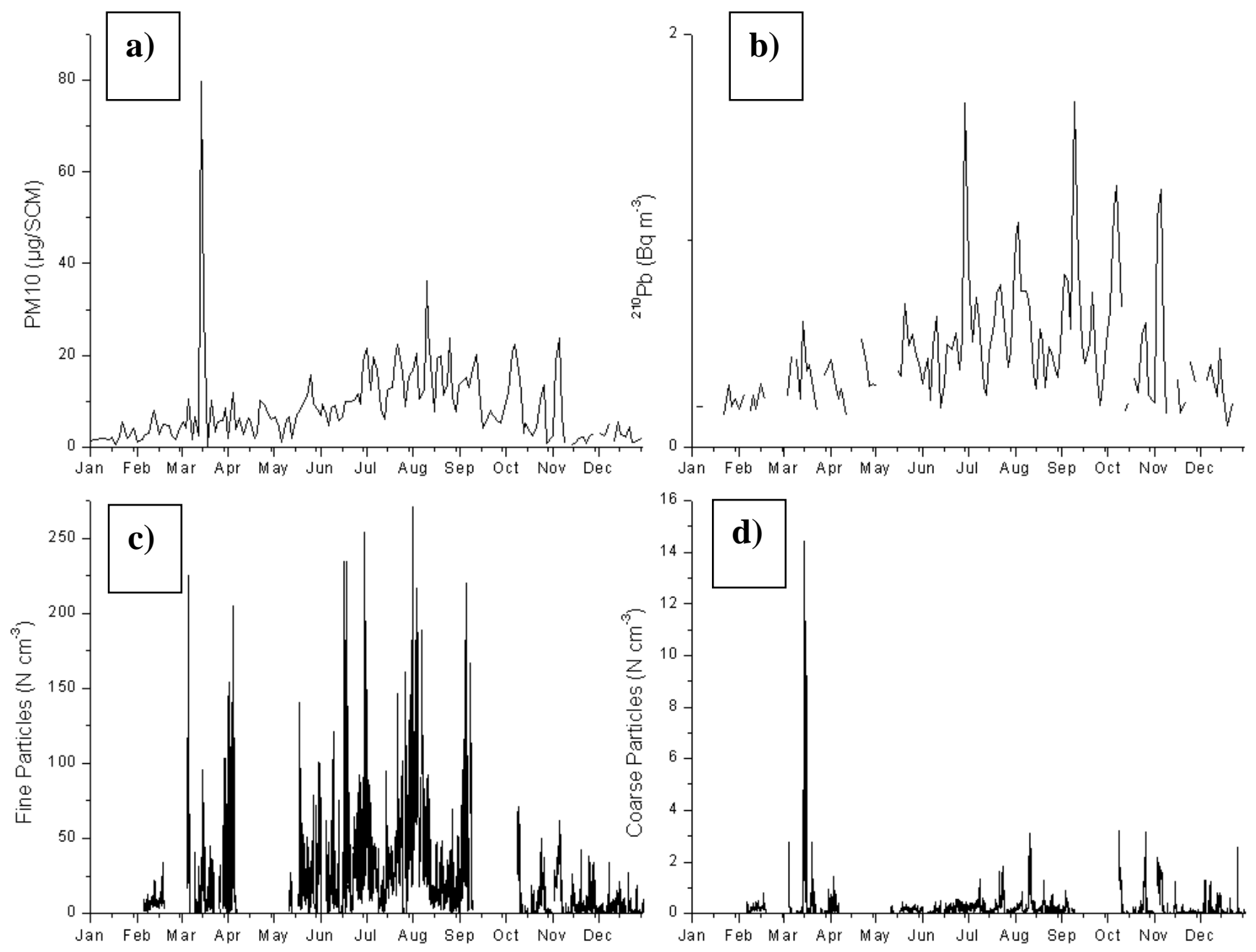

Figure $1(\boldsymbol{a}, \boldsymbol{b}, \boldsymbol{c}, \boldsymbol{d})$. Trend of PM10 (a), ${ }^{210} \mathrm{~Pb}(b)$, number of fine particles $(c)$ and coarse particles $(d)$ for the year 2004 at Mt. Cimone.

At the end of this extraordinary episode, the sequence of two main meteorological patterns: 1) the penetration of an upper-level trough to low latitudes with a minimum centered over the North-western Algerian coast; and 2) a Sahara high extending all over the Mediterranean Sea with an elongated northeastward tongue, mobilized dust to the south of the northern Atlas Mountains in Morocco and western Algeria. The development of a steep gradient between a trough and a Saharan high along the Western Sahara and the western Mediterranean basin is a typical condition during which dust is rapidly transported toward the central Mediterranean.

The aerosol optical depth at the beginning of the second dust outbreak (on $13^{\text {th }}$ March, 2004) and the average over the period 10-15 March 2004 clearly show the severe dust outbreaks across the Atlantic and the Northern part of Italy: during this event the monitoring site at Mt. Cimone has found along the 
main axis of the dust plume, and recorded a concentration as high as $80 \mu \mathrm{g} / \mathrm{SCM}$. Detailed analysis of the event is discussed and presented. 